\title{
Las epístolas del abismo de U go Foscolo: Tres modalidades del suicidio discursivo en Ultime lettere di Jacopo O rtis
}

\author{
Santiago Juan-N aVarro \\ Florida International University, U niversity Park \\ E-mail: Navarros@servax.fiv.edu
}

\section{Resumen}

En su obra más conocida (UItime letteredi Jacopo 0 rtis), el autor italiano del siglo XVIII U go Foscolo reúney explora los motivos y técnicas tradicionalmente asociados al género epistolar. Esta reflexión se materializa en tres niveles discursivos: amoroso (búsqueda de la plenitud personal a través de un objeto de deseo), político (lucha por la unidad e identidad nacionales) y literario (creación de una nueva forma de expresión y de una nueva audiencia). En cada uno de estos tres niveles las contradicciones del protagonista, Jacopo 0 rtis, le sitúan en un callejón sin salida del que sólo puede escapar mediante su autodestrucción. La intención del presente ensayo es estudiar cada uno de estos niveles en relación con la estructura epistolar de la novela de Foscolo. Aunque tales niveles discursivos (amoroso, político y literario) tienden a ser considerados por separado, en mi ensayo planteo una correlación íntima de los tres a la luz de las teorías de Roland Barthes (Fragmentsd'un discoursamoureaux), M ikhail Bakhtin (Problemsin D ostoevskys Poetics) y Jacques D errida (D ela grammatologie y L'écriture et la différence). M i análisis contempla la fragmentación del material narrativo y la dispersión de sus voces y destinatarios como reflejo de la escisión espiritual característica del hombre romántico y de la desintegración política de Italia a comienzos del siglo XIX. Por otro lado, considero que la tensión resultante del enfrentamiento entre postulados estéticos (neoclasicismo y romanticismo) y conceptos excluyentes (artificiosidad y espontaneidad, escritura y oralidad) tiende, en última instancia, a problematizar el acto mismo de escribir y, por lo tanto, la basemisma del género epistolar.

Palabras claves, U go Foscolo, U Itime lettere di Jacopo O rtis, siglo XVIII, neoclasicismo, romanticismo, novela epistolar, discurso amoroso, política, fragmentación, dialogismo, Barthes, Bakhtin, D errida.

\section{Abst Ract}

In his best known work (U Itimelettere di Jacopo 0 rtis) eighteenth-century Italian author U go Foscolo compiles and explores motifs and techniques that weretraditionally associated with the epistolary genre. This reflection materializes itself on three discursivelevels: 
the discourse of love (search of individual plenitude through an object of desire), political discourse (fight for national independence and unity), and literary discourse (development of both anew form of expression and anew readership). $0 \mathrm{n}$ each of theselevels the contradictions of the protagonist, J acopo 0 rtis, placehim in a dead end from which hecan only escape through self-destruction. This essay aims at discussing each of these levels in relation to the epistolary structure of the novel. Aulthough these discursive levels (love, politics, literature) tend to be considered independently, I pose an intimate correlation among the three in the light of the theories of Roland Barthes (Fragments d'un discours amoureaux), M ikhail Bakhtin (Problemsin D ostoevsky'sPoetics), and Jacques D errida (D ela grammatologie and L'écritureet la différence). My anal ysiscontemplates thefragmentation of the narrative material and the dispersion of voices and addressees as a reflection of the spiritual schism of the Romantic mind, as well as of the political disintegration of I taly on the eve of the nineteenth century. I also consider thetension that resultsfrom the confrontation of opposed aesthetic postulates (N eoclassicism and Romanticism), and concepts (artifice and spontaneity, writing and orality). This opposition ultimately tends to problematize the act of writing and, therefore, the very base of the epistolary genre.

Keywords: U go Foscolo, U Itime lettere di Jacopo O rtis, 18th Century, Neoclassicism, Romanticism, epistolary novel, lover's discourse, politics, fragmentation, dialogism, Barthes, Bakhtin, D errida

E N U Itime lettere di Jacopo O rtis, U go Foscolo explora los motivos y técnicas - tradicionalmente asociados al género epistolar. Esta reflexión se materializa en tres niveles discursivos: amoroso (búsqueda de la plenitud personal a través de un objeto de deseo), político (lucha por la unidad e identidad nacionales) y literario (creación de una nueva forma de expresión y de una nueva audiencia). En cada uno de estos tres niveles las contradicciones del protagonista, Jacopo O rtis, le sitúan en un callejón sin salida del que sólo puede escapar mediante su autodestrucción. La intención del presente ensayo es estudiar cada uno de estos niveles en relación con la estructura epistolar de la novela de Foscolo.

La fragmentación del material narrativo y la dispersión de sus voces y destinatarios son reflejo de la escisión espiritual característica del hombre romántico y de la desintegración política de Italia a comienzos del siglo XIX. Por otro lado, la tensión resultante del enfrentamiento entre postulados estéticos excluyentes (neoclasicismo y romanticismo, artificiosidad y espontaneidad, escrituray oralidad) tiende, en última instancia, a problematizar el acto mismo de escribir y, por lo tanto, la base misma del género epistolar.

Ultime lettere es considerada por algunos críticos como la primera novela propiamente italiana ${ }^{1}$. En la redacción de lo que los críticos consideran el germen de su novela (el "Proto O rtis"), Foscolo se valió de los modelos existentes en el siglo XVIII. La mayoría de ellos estaban construidos siguiendo las pautas

${ }^{1}$ Veáse en este sentido el comentario de Radcliff-U mstead en su introducción a la traducción inglesa de las cartas (1970a:10). 
del modo epistolar. Especial influencia tuvieron en Foscolo Pamela deRichardson (sobre la que escribiría un ensayo) y La N ouvelle H éloïse de Rousseau. En su forma original la obra de Foscolo tenía como escenario Venecia antes del tratado de Campoformio, por el cual la República de Venecia pasó a manos de Austria. Bajo el título inicial de Laura, lettere, Foscolo escribió un romance sentimental inspirado en la tradición amorosa de Petrarca. Fue precisamente el mencionado tratado y la situación del autor como proscrito y exiliado, lo que le llevó a darle a la novela una orientación política. Al mismo tiempo, la lectura del recientemente aparecido Werther de Goethe tuvo un impacto decisivo en el autor italiano ${ }^{3}$. El resultado de estas confluencias fueU Itime lettere de Jacopo 0 rtis, donde la corrupción política de Italia y losinfortunios amorosos llevan al protagonista al suicidio.

La llamada edición londinense de la novela (publicada realmenteen Zurich) aparece dividida en dos partes que incluyen un total de aproximadamente setenta cartas y abarcan un período de cerca de tres años (desde el 11 de octubre de 1797 hasta el 20 de marzo de 1799)4. La extensión y el contenido de las mismas va desde largas confesiones amorosas y digresiones políticas a breves notas o misivas escritas apresuradamente. En ellas Jacopo, un joven burgués envuelto en las luchas políticas de la Italia del momento, confiesa a su amigo Lorenzo su amor apasionado y su descontento ante la situación del país. El encuentro con la heroína se produce cuando Jacopo huye de Venecia por razones políticas. Camino del exilio traba amistad con un tal Signor $T * * *$ y sus dos hijas (I sabella y Teresa). Al comprender que se está enamorando de Teresa y que su relación es imposible (la joven esta prometida al noble 0 doardo), Jacopo

${ }^{2} \mathrm{Al}$ parecer, esta primera aventura epistolar de Foscolo no fue más allá de un simple expe rimento, un borrador que el autor se vio obligado a presentar a sus editores a pesar de que él mismo lo considerara incompleto: "Q uesto libro non è interamente compiuto, ma l'autore è costretto a dargli I'ultima mano quando anche egli non volesse" ("Piano di Studi," en Opere, VI, p. 6; citado por N icoletti 1978:49n12).

${ }^{3}$ La influencia de G oethe se convirtió desde el principio en un lugar común de la crítica foscoliana. El propio autor no ignoraba esta posibilidad y dejó constancia de las diferencias entre su obra y la de G oethe en el apartado VI de su "N otizia bibliografica" (1970:504-527). Aunque la mayor parte de los ensayos sobre Foscolo tratan este tema, son de especial interés las monografías de Graff (1895), M arpillero (1900), Zumbini (1905), D apelo (1953), M assano (1965), y M anacorda (1973), así como el estudio de Radcliff-U mstead (1970b:54-55).

${ }^{4}$ El cómputo se hace difícil ya que en ocasiones las cartas quedan interrumpidas para interpolar fragmentos de otras o los comentarios del supuesto editor. La confusión es aún mayor al existir tres versiones distintas de U Itime lettere. Las citas de la novela que recoge el presente trabajo provienen del cuarto volumen de la Edizione $\mathrm{N}$ azionale delle 0 pere di U go Foscolo (1970). En esta edición de sus obras completas se reproducen íntegramente las tres versiones existentes: Bolonia (1798), M ilán (1802) y Zurich (1816). La quelos críticos Ilaman edición londinense es, en realidad, una reimpresión de la versión de Zurich que M urray publicó en la capital inglesa un año después. 
emprende un exilio no ya sólo político, sino también espiritual, al que sólo pondrá fin mediante el suicidio.

A esta trama, aparentemente sencilla y evocadora de buena parte de los clisés de la novela sentimental, se contrapone una complejidad narrativa que va más allá del básico circuito emisor-receptor propio de la novela epistolar. La voz narrativa predominante al comienzo de la novela es, sin duda, la de Jacopo. Lorenzo, por su parte, se limita a cumplir su papel como editor de las cartas que a través de emisarios recibe del protagonista. Conformeel discurso de esteúltimo va haciéndose cada vez más fragmentario, como consecuencia de su derrumbamiento emocional, la figura de Lorenzo va adquiriendo un mayor peso específico en la novela 5 . En muchos sentidos podríamos llegar a decir que se convierte en el protagonista, 0 al menos, en el orquestador de esa sinfonía caótica en vías de desintegración que es el pensamiento de Jacopo ${ }^{6}$. Lorenzo organiza cronológicamente cartas y fragmentos que recibe, no ya mediante un mensajero, sino a través del correo. En muchas ocasiones se producen espacios de indeterminación entre unas cartas y fragmentos, que Lorenzo debe resolver mediante sus comentarios en primera y tercera persona.

Aun cuando la novela adquiera ocasionalmente el modo narrativo más común (la tercera persona), Lorenzo se cuida de insistir desde el principio en la veracidad delo narrado (afirma haber presenciado los hechos, o haberlos recogido fielmente de testigos oculares $)^{7}$. Las cartas del propio Lorenzo y de Teresa son ocasionalmente reproducidas en U Itime lettere, en el primer caso como citas inscritas en cartas de Jacopo, en el segundo, como resultado de la labor compiladora de Lorenzo. U na voz menos clara, pero presente en toda obra literaria, es la del autor implícito, entendido éste como "the governing consciousness of the

${ }^{5}$ El carácter fragmentario de la narrativa foscoliana ha sido interpretado de modo muy diverso por los críticos. Lo que para unos es defecto estilístico, para otros es una gran innovación de la técnica narrativa. D e cualquier modo, parece razonable atribuir, como hace Verna tal fragmentarismo a la estructura propia del discurso epistolar. Esta última es la postura de Verna que en su ensayo sobre Foscolo ("D al frammento all'unità: la struttura epistolare delle U Itime lettere di Jacopo O rtis", en Pugliese 1989:31-39) pretende "illustrare come certi aspetti del ben noto frammentismo della scrittura foscoliana costituiscano un tutt'uno non solo con le istanze ideologiche e morali del N ostro, ma anche, e non meno significativo, con la struttura stessa dell'opera che andiamo analizzando" (1989:31).

${ }^{6}$ Esta idea la desarrolla Verna en el ensayo arriba mencionado: "Tale sarà lo spessore di questa sua obliqua presenza testuale che essa finirà col conferire a Lorenzo lo status di un vero personaggio romanzesco..." (1989:35).

${ }^{7}$ Al igual que el Werther de G oethe, U Itime lettere se abre con una advertencia al lector escrita por el destinatario y supuesto editor de las cartas (W ilhelm, en el primer caso; Lorenzo en el segundo). Tanto W ilhelm como L orenzo insisten en su tarea objetiva de recopiladores de hechos verídicos y solicitan la simpatía del lector en relación con las desventuras de sus protagonistas. 
work as a whole, the source of the norms embodied in the work" (RimmonKenan 1983:86). Esta fuerza organizadora que permanece en la sombra articularía las dos voces principales de la novela (Jacopo y Lorenzo) con todos aquellos elementos narrativos que sirven de vehículo al autor para expresar su visión del mundo. Se trata, en suma, de la voz del propio texto expresándose a sí mismo.

La variada gama de voces narrativas que despliega el texto de Foscolo se corresponde con una multiplicación de la figura del destinatario. Aunque Lorenzo es el receptor básico del grueso de cartas recogidas por él mismo, Teresa, el Signor $\mathrm{T}^{* * *}$, la madre de Jacopo, el país y sus héroes, la naturaleza, y hasta $\mathrm{D}$ ios mismo, se revelan como encarnaciones del "tú" o del "voi" a los que se dirige el narrador. A todo ello se añade la figura de lo queW olfgang I ser llama "the implied reader" y que es correlativa al citado concepto del autor implícito: "the reader whom the text creates for itself and amounts to 'a network or response-inviting structures', which predispose us to read in cetain ways' (Selden 1986:112).

En los tres apartados siguientes comentaré la articulación (y en ocasiones desarticulación) de estos emisores y destinatarios en relación con los tres niveles discusivos mencionados y los motivos principales del género epistolar.

\section{1. "JE EST UN AUT RE": AM OR, AMISTAD, MUERTE, YEL DIALOGO CON EL OTRO}

"Fratelli, a un tempo stesso, Amoree M orte"

La carta como "forma de relación individual y social" (Guillén 1985:169) ofrece el marco perfecto para el dialogismo que propone Bajtin en su teoría de la novela. El género epistolar, asimismo, dramatiza el carácter comunicativo queel crítico ruso ve como uno de los elementos clave en la formación de las formas novelísticas. D e especial relevancia para el tema que estamos tratando es su concepto de la "otredad." Aunque la antropología filosófica de Bajtin es sumamente compleja y, en ocasiones, contradictoria (Todorov 1984:100), me limitaré a subrayar algunas ideas básicas en relación con el concepto de la otredad y su relación con la creación literaria.

Para Bajtin es imposible concebir nuestra propia identidad al margen de la presencia del otro. Somos conscientes de nuestro ser físico y psicológico a través de la percepción y la conciencia de los demás. Esto lleva a Bajtin a establecer la absoluta necesidad estética que el ser humano manifiesta por su semejante. La estructura epistolar al egorizaría, por tanto, ese "intenso encuentro" entre el yo y el otro que Bajtin considera imprescindible para alcanzar el autoconocimiento. 
D esde este punto de vista, ser significa comunicar, y para que la comunicación tenga efecto, aunque resulte obvio decirlo, es imprescindible la presencia de un destinatario: "The very being of man (both internal and external) is the deepest communion. To be means to communicate.. To be means to be for another, and through the other, for oneself" [énfasis del autor] (Bajtin 1984:287).

La carta actúa como vehículo en este acto comunicativo: conector entre dos puntos distantes, puente que se tiende entre un emisor (yo-presente) y un receptor (el otro-ausente). Como sugiere Altman, el autor epistolar puede enfatizar tanto la distancia como el puente, el medio (1982:13). En Ultime lettere veremos cómo Jacopo, la voz narrativa principal, recurrealternativamentea ambas posibilidades. La forma misma de la carta parece apropiada para el argumento amoroso por su énfasis característico en los motivos de la separación y el encuentro ${ }^{8}$. El héroe romántico de Foscolo es consciente de esta interrelación entre estos dos motivos, de la forma en que el propio medio de comunicación refleja tanto la presencia como la ausencia del destinatario.

En la obra de Foscolo, el discurso amoroso aparece entrelazado con el de la amistad. Las cartas, salvo unas pocas excepciones, van todas destinadas al amigo íntimo, al confidente: Lorenzo ${ }^{9}$. El discurso amoroso de Jacopo se deduce así a través de sus comentarios indirectos. El carácter suicida del mismo queda establecido desde los comienzos de la obra, debido a la imposibilidad de que su amor por Teresa pueda llegar a materializarse en un encuentro definitivo. La negativa de Jacopo a aceptar la inevitable y creciente ausencia de su amada le lleva a una situación insostenible que sólo puede resolverse en el suicidio.

\footnotetext{
${ }^{8} \mathrm{La}$ carta funciona, tanto en Foscolo como en Goethe, como vehículo estructurador de la producción de significado que, según Barthes, desata el arrebato amoroso: “Werther n'est pas pervers, il est amoureux: il crée du sens, toujours, partout, de rien, et c'est le sens qui le fait frissonner: il est dans le brasier du sens" (1977:81). En tanto vehículo, la carta actúa por desplazamiento metonímico, como sustituto incompleto del objeto de deseo. El discurso amoroso, el galanteo, se convierte de esta forma en manifestación de un juego erótico indefinido: "le langage est une peau: je frotte mon language contre l'autre... M on langage temble de désir... (Parler amoureausement, c'est dépenser sans terme, sans crise; c'est pratiquer un rapport sans orgasme. II existe peut-être une forme littéraire de ce coïtus reservatus: c'est le marivaudage)" (1977:87). Aunque las cartas recogidas en la novela deFoscolo van en su mayor parte dirigidas a Lorenzo, en ellas recrea Jacopo su relación con Teresa y en especial todos aquellos momentos de contacto físico o espiritual con la amada.

${ }_{9}^{9}$ I gualmenteen Werther el editor. Wilhelm, es el destinatario de prácticamentela totalidad de las cartas. Sólo dos de ellas van dirigidas a la amada Lotte. Al igual que Lorenzo, W ilhelm irá cubriendo los espacios de ambigüedad que se van creando a medida que las cartas se van haciendo más fragmentarias. El uso de la tercera persona para describir los últimos momentos de los protagonistas es común en las páginas finales de las dos novelas, como lo son también las llamadas de atención al lector.
} 
Para poder comprender este proceso autodestructivo, mediante el cual el objeto de deseo se manifiesta como definitivamente inal canzable y ausente, sería conveniente establecer la estructura general de U Itime lettere.

Las diez primeras cartas funcionan a modo de prefacio, presentando el escenario, los personajes principales y los temas dominantes. En concreto, las cuatro cartas que cubren el período del 11 al 19 de octubre introducen las ideas políticas y morales de Jacopo, explicando sus circunstancias personales. El presagio de la muerte se manifiesta desde un principio mediante un recurrente y obsesivo simbolismo sepulcral. Las tendencias suicidas de Jacopo aparecen ya en la segunda de sus cartas (13 de octubre de 1797). La introducción de veladas alusiones a la trágica historia de L auretta y a la muerte de su amado Eugenio sirven para consolidar esta nota ominosa en la que el lector empieza a presentir el triste desenlace de una historia que aún no ha comenzado ${ }^{10}$. No es hasta la séptima de las cartas que el lector tiene conocimiento de Teresa como un ser de belleza extraordinaria. Las tres siguientes completan la obertura de la obra recalcando los temas principales (desilusión política, tensión vida/muerte, ostracismo de Jacopo, premonición de su final). Toda la historia de Jacopo aparece resumida en la carta del 20 de noviembre. A partir de aquí el argumento aportará muy poco de nuevo. El propio Foscolo, adelantándose a críticas desfavorables por el carácter estático de la línea argumental, aclaró este punto en su "notizia bibliografica"11. Lo que nos interesa por el momento es establecer el progreso dela relación entre acopo y Teresa. Es precisamente en esta undécima carta donde Jacopo declara abiertamente su amor por la joven, reconociendo a un mismo tiempo los obstáculos para su pasión. Teresa, por su parte, confiesa su infelicidad ante el futuro enlace matrimonial con 0 doardo. Pero el dato más significativo de este pasaje viene dado por el énfasis de Jacopo en el hecho de que sólo Teresa es capaz de compartir con él su apreciación de la naturaleza. En sus descripciones de la belleza in efable del paisaje, Teresa es simultáneamente descrita como un ser rodeado de

${ }^{10} \mathrm{D}$ e hecho, el título mismo de la novela de Foscolo, U Itime lettere di Jacopo Ortis, es ya de por sí indicativo de los motivos de la muerte y el acabamiento que recorren cada una de sus páginas.

${ }^{11}$ Foscolo reconoce que "gli avvenimenti tutti che danno principio, progresso e catastrofe all'azione sono coś scarsi e miseri, che ove si prescinda dagli episodi non basterebbero a dar moto a un cortissimo dramma; e sono tessuti in guisa che il lettore li prevede da sé innanzi tratto; difetto capitale d'arte di cui l'autore o compilatore che sia il quale pubblico il libro, saccorse sí poco, che l'eroe disperato della prima lettera è pure, né sí poco, chel'eroe disperato della prima lettera èpure, ne meno, il disperato dell'ultima..." (488; citado en M atteo 1985:241). La obra de 0 rtisfigura como radiología del espíritu de un ser atormentado. En lugar de ofrecer una descripción lógica delas etapas quele conducen al suicidio (como haceG oetheen Werther), Foscolo prefiere detenerse recurrentemente en las contradicciones entre las que se debate Jacopo. La tensión de la novela deriva no ya del argumento, sino de la compleja psicología del personaje. 
un aura resplandeciente. Sólo ellos dos pueden llegar a sentir el pulso cósmico del universo.

H asta aquí lo expresado abiertamenteen la superficiedel texto: las compulsivas declaraciones de Jacopo en medio de su neurosis amorosa. Cabe preguntarse hasta qué punto Teresa es un ser real, o simplemente responde a la proyección del deseo insatisfecho de acopo $^{12}$. H asta quépunto el objeto amoroso comparteel sentimiento de Angst del protagonista, o sólo responde a un intento de este último por focalizar y trascender su angustia existencial ${ }^{13}$. Recordemosque, conforme a la noción de la otredad expuesta anteriormente, únicamente somos capaces de formularnos a nosotros mismos a través del otro. Teresa y Lorenzo cumplen, aparentemente, esa función que permite a Jacopo llegar a ser él mismo. Pero Teresa cierra desde el principio toda posibilidad de una relación amorosa plena. En el texto su actitud es justificada por el protagonista. Teóricamente debe obedecer la voluntad de su padre, el cual, a su vez, favorece la boda con 0 doardo debido a presiones políticas y a razones económicas. El texto encubre, en realidad, un discurso ideológico mucho más poderoso quelas anécdotas sentimentales que Foscolo tomó prestadas de $\mathrm{G}$ oethe. Como discutiremos en un segundo apartado, Jacopo pertenece a una clase inferior y sus aspiraciones de ascenso en la escala social nada tienen que hacer ante la presencia del noble 0 doardo. La sumisión de Teresa a la voluntad paterna no parece acomodarse al imperio de la pasión que domina la sensibilidad romántica.

${ }^{12}$ Teresa se convierte en la imaginación de Jacopo en encarnación de lo natural, lo auténtico, la inocencia perdida, en compendio de todos esos principios centralizadores que, según Derrida, han dominado el pensamiento "Iogocéntrico"occidental. En su crítica de Lévi-Strauss, D errida (1967a) establecela inexistencia de un estado de pura inocencia o autenticidad. Estos términos, sublimados por la tradición romántica, se hallan en permanente interacción con su opuesto (naturaleza/cultura, autenticidad/ falsedad, inocencia/perversión). Privilegiar uno de los elementos del binomio, establecer una jerarquía, es perpetrar un acto de violencia contra el carácter ambivalente del signo. El fracaso amoroso de Jacopo se produce, entre otras razones, como consecuencia de su incapacidad para armonizar los elementos de esta cadena de oposiciones. La tensión resultante le lleva a buscar en la muerte un descanso a su mente atormentada.

${ }^{13} \mathrm{~L}$ os comentarios deBarthes en relación con el personaje de Charlotteen Werther podrían muy bien aplicarse a la figura de Teresa en UItime lettere. Como Lotte, Teresa no tiene valor alguno en la novela salvo en relación con el protagonista. Frentea la violenta pasión de Jacopo, la joven ideal izadano pasa de ser un personaje pál ido y desdibujado, un ser inexistente: "C harlotte est bien fade; c'est le piètre personnage d'une mise en scène forte, tourmentée, flamboyante, montée par le sujet Werther; par une décision gracieuse de ce sujet, un objet fal ot est placé au centre de la scène, et là adoré, encensé, prisà partie, couvert de discours, d'oraisons..." (1977:39). El carácter reflectante del objeto amoroso es, asimismo, comentado por Barthes en términos que se corresponden con la actitud de Jacopo: "c'est mon désir que je désire" (ibid.). Rafael Argullol considera esta misma concepción narcisista del amor como característica dela sensibilidad romántica: "El enamorado romántico no ama seres reales concretos; ama su propia concepción del amor que él evoca atribuyéndolo a su amante" [énfasis del autor] (1982:286). 
Lorenzo, su confidente, amigo y compañero en la lucha política, es por tanto el único que puede ayudar a Jacopo a realizarse plenamente como ser humano. Y Lorenzo aconseja a Jacopo la huida no sólo de los peligros asociados con la tiranía que gobierna la República de Venecia, sino también del peligro que suponetoda relación con la familia del Signor $T^{* * *}$ (representativa de la aristocracia responsable de la situación del país). Jacopo decide no hacer caso de los consejos de su amigo, para hundirse de lleno en el abismo que se le ofrece en la falsa calma de las Colinas Eugenias. Su decisión de abrazar una causa perdida de antemano (su amor por Teresa) supone el primero de los suicidios mencionados ${ }^{14}$.

\title{
2. ENTRE EL TITANISMO Y LA DEPRESION : EL DISCURSO POLITICO DE JACOPO ORTIS
}

\author{
Names arethere, $N$ ature's sacred watchwords, they \\ Were borne al oft in bright emblazonry; \\ The nations thronged around, and cried aloud, \\ As with one voice, Truth, Liberty and Love! \\ Suddenly fierce confusion fell from heaven \\ Among them: there was strife, deceit, and fear: \\ Tyrants rushed in, and did divide the spoil.
}

Como ya hemos apuntado el discurso amoroso y el propiamente ideológico y político aparecen entrecruzados en la obra de Foscolo. En ocasiones el primero parece subordinado al segundo, lo que conferiría a la obra su original idad frente al Werther de $G$ oethe ${ }^{15}$. La primera carta, de hecho, se abre con una invectiva contra $\mathrm{N}$ apoleón por haber traicionado a la República deVenecia, dejándola en manos de Austria. El Tratado de Campoformio se convierte pronto en uno de los leit-motifs de la novela. La firma de este tratado representa para toda una

${ }^{14}$ Parece significativo el hecho de que Jacopo decida poner fin a su vida clavándose una daga en el corazón. Werther, en cambio, se dispara en la cabeza, "por encima del ojo derecho." El acto de Werther es una reafirmación última del poder del sentimiento frente a la razón. La muerte de Jacopo, sin embargo, se revela como un eslabón más en la larga cadena de autonegacionesquecaracteriza su pensamiento. D estruye aquello quemás estima ("tutto dipende dal cuore"). Su suicidio deviene destrucción simbólica del deseo, autocastración, ya que como sugiereBarthes, "le cœur est l'organe du désir (le cœur segonfle, défaille, etc., commele sexe)..." (1977:63).

15 “Foscolo's U Itime lettere di Jacopo O rtis, very much influenced by Werther, adds to the Wertherian suicide motif a perennial Italian concern: despair over the state of the father land" (Altman 1982:148). 
generación deitalianos la pérdida de la fe en los logros dela revolución francesa y el fin de las esperanzas en la unificación del país ${ }^{16}$.

Las primeras líneas de la novela son al tamente significativas en este sentido: "Il sacrificio della patria nostra èconsumato; tutto è perduto... Poichèho disperato e della mia patria e di me, aspetto tranquillamente la prigione la morte" (295). El punto de arranque de la obra tiene como protagonista a un ser desilusionado y en espera de la muerte; exactamente las mismas características de Jacopo hacia el final. La finalidad de esta carta es, como sugiere Radcliff-U mstead, conectar Ios sucesos dela novela con la situación política: "T he novelist wished to present the tragedy of his hero as part of a larger national tragedy" (1970:50) ${ }^{17}$.

La indignación que provoca en Jacopo este hecho, se ve acrecentada por la corrupción política del país y el olvido de los héroes nacionales. Este panorama desolador provoca en él un sentimiento de indignación que, sin embargo, nunca llega a cuajar en una actividad política inmediata. Jacopo vocifera, se revuelve

${ }^{16} \mathrm{H}$ asta que el 18 de febrero de 1861 se reunió en Turín el primer parlamento autónomo italiano, la patria de Foscolo fue objeto de la especulación de las grandes potencias. En 1748 la Guerra de Sucesión Austríaca terminó con el Tratado de Aix-la-Chapelle. D e acuerdo con este pacto Austria, Francia y España repartían su hegemonía sobre el territorio italiano. La Revolución Francesa tuvo una importante repercusión en I talia, trayendo consigo nuevas condiciones y nuevas ideas. En 1796 N apoleón cruzó los Alpes a la cabeza del ejército francés y ocupó las ciudades más importantes del norte del talia. Su triunfo fue facilitado por el apoyo recibido por parte de los liberales italianos que veían en N apoleón a un abanderado de los ideales de la revolución burguesa. Entre estos liberales se encontraba el propio Foscolo, autor de una oda "A Bonaparte, il liberatore". La posterior derrota de los franceses obligó a ceder importantes territorios a Austria, entre ellos, la República deVenecia. La llamada "traición" de N apoleón habría decompletarse mediante una interminable serie de invasiones queterminaron con el Congreso de Viena (1814-1815). Las posiciones de las superpotencias que resultaron de este congreso venían a ser las mismas que las de 1789 ó 1795. La edición londinense de la U Itime lettere fue publicada en 1817. Cabe suponer que la intención de Foscolo al dar una orientación más política a su obra era denunciar el hecho de que su patria fuera objeto de tráfico entre las potencias extranjeras. En su carta del 19 de enero de 1797, Jacopo exclama "Venezia era trafficata." Aunque alude directamente al Tratado de Campoformio, Foscolo denuncia una situación que demostró ser recurrente en la historia de I talia hasta su unificación definitiva en la segunda mitad del siglo XIX. Las circunstancias históricas de este período son objeto de meticuloso estudio en los en sayos de C arpanetto y Ricuperati (1987) y H earder (1987).

${ }^{17}$ D e hecho, Foscolo cambió la fecha inicial de la carta. En la edición bolognesa figuraba como escrita el 3 deseptiembre de 1797. En la versión milanesa lleva por fecha el 2 de octubre, recibiendo definitivamente la del 11 de octubre (edición londinense), fecha en que Bonaparte se allegó a Udine con los austriacos para firmar el tratado. La firma fue completada en Campoformio el 17 del mismo mes. Por medio del tratado, la República de Venecia pasó a formar parte del imperio austriaco. C omo señala Altman, "Foscolo's particular concern in the final version of the novel (1802), is the concession of Venice to the Austrians in the Treaty of Campo Formio" (1982:148). 
y llama a la rebelión. Pero sus gritos son la voz del profeta que clama en el desierto. Su audiencia consiste en una naturaleza indiferentey a menudo hostil, en labriegos que le miran absortos como a un ser estrafalario, o en Lorenzo, a quien es innecesario convencer, porque compartelasmismas ideas que Jacopo ${ }^{18}$.

M uchas de las digresiones de carácter político en la que se embarca el héroe de Foscolo parten de las reflexiones provocadas por las lecturas de los clásicos y los grandes del renacimiento italiano (D ante, Petrarca, etc. $)^{19}$. En la cuarta carta (18 de octubre de 1797), por ejemplo, un libro de Plutarco que recibe de Lorenzo le sirve a Jacopo para consolarse "de' delitti e delle sciagure dell'umanità volgendo gli occhi ai pochi illustri che, quasi primati dell'umano genere, sovrastano a tanti secoli e a tante genti" (297). Las consecuencias literarias de este contradictorio y constante volver los ojos a los clásicos las discutiré en el último apartado de mi trabajo. Baste de momento señalar el talante aristocrático que se percibe desde el principio en el discurso del protagonista. Esquemáticamente el pensamiento político de Jacopo sigue estas pautas: denuncia de una situación de injusticia, indignación no correspondida (pues sólo unos pocosson capaces de reconocer los males del país), regreso a un pasado prístino y legendario.

Como hemos señalado anteriormente, Jacopo es representante del nuevo orden burgués que pretende desplazar del poder a la viejas y corrompidas estructuras de la nobleza. Pero el pensamiento de Jacopo funciona a menudo según las pautas de la caduca aristocracia que pretende derribar: individualismo, desprecio del vulgo, respeto por las clases y la propiedad privada, etc. Su fascinación por la familia del Signor T*** ( familia de origen patricio y, por lo tanto, fuera del alcance de Jacopo) es sintomática de su deseo de promocionarse socialmente ${ }^{20}$. Lorenzo actúa aquí como la voz de su conciencia política que le

${ }^{18} \mathrm{D}$ e hecho, tanto los comentarios directos del editor como aquellos que se desprende de las cartas del protagonista, nos hacen imaginar a Lorenzo como un ser prudente capaz de una visión política más perspicaz, menos histriónica, pero no por ello menos revolucionaria.

${ }^{19}$ En varios momentos de la narración Jacopo muestra su adoración por los héroes literarios nacionales, visitando sus tumbas o aquellos lugares donde vivieron. En la carta del 20 de noviembre de 1797 (la famosa undécima carta), Jacopo describe su peregrinación a A rquà para visitar la que fuera casa de Petrarca. El estado ruinoso en que se encuentra sirve de motivo para una larga digresión sobre el olvido en el que han caído los grandes dela cultura italiana. Poco antes de morir (el 5 de marzo de 1799) Jacopo culmina su periplo sepulcral ante la tumba de $D$ ante, con quien se siente profundamente identificado.

${ }^{20}$ En el fondo Jacopo anhela, como Werther, ser encasillado, pertenecer, ya sea a un núcleo social mínimo como la familia, la nación o la comunidad humana en general. Pero, al mismo tiempo considera esta integración como un acto de renuncia a su Yo único. Este individualismo feroz y el sentimiento de rechazo que su personalidad antisocial despierta a su alrededor 
insta a alejarse de esta familia, esto es, de la aristocracia, para retomar la lucha política en el exilio. Pero Jacopo desoye las advertencias de su amigo ${ }^{21}$.

El magnetismo que ejercen sobre él los delicados miembros de esta familia deviene versión blanda y encubierta de la recurrente atracción del abismo que aturde los instintos de la mente romántica. El Signor T*** es claramente un ser tan tiránico como los déspotas responsables de la venta de Venecia a una potencia extranjera. Fuerza a su hija a contraer un matrimonio no deseado con 0 doardo, noble y acaudalado. Lo que podría parecer un lugar común en la tradición de la novela sentimental, adquiere una lectura ideológica que no podemos dejar de subrayar. El enlace forzado de 0 doardo y Teresa provoca la separación del Signor $\mathrm{T}^{* * *}$ con su mujer, que se oponeal matrimonio y es significativamente "exiliada" de las C olinas Eugenias. La acción autoritaria del padre provoca, en última instancia, la infelicidad de Teresa y, en parte, el suicidio de Jacopo. La anónima madre de Teresa y el personaje central comparten su condición de exiliados, pero mientras la primera se enfrenta a la autoridad patriarcal, J acopo no sólo la acepta, sino que, en ocasiones, la justifica. El Signor $T^{* * *}$ es, alos ojos deJ acopo, un ser justo y ecuánime que, si toma alguna decisión moralmente cuestionable, lo hace siempre forzado por las circunstancias y en defensa de los intereses familiares. Teresa, en su respeto a la voluntad paterna, muestra, según el protagonista, la virtud de la obediencia y la resignación, una virtud ajena (podríamos decir que antitética) al espíritu romántico y que Jacopo no siempre comparte.

La propia estructura de la novela revela, asimismo, el discurso ideológico de Jacopo: imperio y progresiva desintegración del Yo, tensión entrela pasión (romanticismo) y la razón (neoclasicismo), voluntad democrática y tendencias aristocratizantes. El aparente diálogo inherente al género epistolar es puesto en duda por el discurso monológico de Jacopo. En U Itimelettere el Yo no es definido por el Tú, como en otras obras más propiamente epistolares. Foscolo se siente más cercano a G oethequea Rousseau. A diferencia de la N ouvelleH éloïs, donde varios destinatarios reciben las cartas de numerosos remitentes, tanto en

provocan la soledad del héroe romántico, fuente de euforia pero también de envidia, paranoia y depresión: "Le sujet amoureux voit tous ceux qui I'entourent casés, chacun lui paraissant pourvu d'un petit système pratique et affectif de liaisons contractuelles, dont il se sent exclu; il en éprouve un sentiment ambigu d'envie et de dérision" (Barthes 1975:55).

${ }^{21}$ A diferencia del sujeto "cuerdo", racional, el sujeto amoroso rechaza escoger entre dos alternativas en los momentos de crisis. Su actitud es la de persistir en su irracionalidad, escapar a la elección. En él opera un deseo masoquista de persistir en el sufrimiento, de ceder a la tentación del abismo: "Tel est lediscours du sujet "sain": ou bien, ou bien. M ais le sujet amoureux répond (c'est ce que fait Werther): j'essaie de me glisser entre les deux membres del'alternative: c'est-à-dire: je n'ai aucun espoir, mais tout de même.. O u encore: je choisis obstinément de ne pas choisir; je choisis la dérive: je continue" [énfasis del autor] (Barthes 1975:75). 
Werther como en U Itime lettere, el diálogo entre los amantes es sustituido por el monólogo del amante angustiado. La carta se convierte así en vehículo de afirmación personal más que de libre intercambio. Las reflexiones de acopo no parecen esperar una respuesta. La primera impresión que tenemos al leer la novela es la ausencia de intercambio epistolar. Pero, como hemos visto al nivel del contenido, la obra de Foscolo rehúye las simplificaciones. Como toda ausencia, el otro polo del esquema comunicativo epistolar semanifiesta en estado latente y surge, a veces, arrebatando el protagonismo al propio Jacopo. Esto ocurre en el caso de Lorenzo, destinatario principal de los desahogos emocionales del protagonista. Tras un detenido análisis de al gunas de estas cartas, se deduce que son las cartas de Lorenzo, en realidad, las que desencadenan la compulsiva fiebre epistolar en Jacopo. Este último escribe a menudo en respuesta a los comentarios y consejos que anteriormente ha recibido de su amigo.

La labor de Lorenzo como editor tiene aún mayores implicaciones en relación con el acto de leer. Lorenzo deviene prototipo del lector competente que no sólo se limita a consumir la obra literaria, sino que la organiza, le da forma y le confiere, en última instancia, su valor estético. D esdeel punto devista diegético, las cartas de Jacopo son simples confesiones que su amigo reúne en un todo consistente. Lorenzo, el destinatario, el lector y editor, es el artífice final de la obra literaria como tal. Transforma la materia prima en novela. En este punto se plantea la ambivalencia ideológica del discurso epistolar en U Itime lettere. EI fragmentarismo de las cartas, invita a la colaboración del lector para llenar los "espacios de indeterminación", los "vacíos textuales" queva dejando tras de sí el propio texto ${ }^{22}$. La novela pretende mostrarse, de esta forma, como espacio democrático para la interpretación, como estructura abierta a la recreación y, por tanto, a la reescritura. Como indica Verna: “Sedavanti allelacune dell'epistolario

${ }^{22} \mathrm{El}$ valor funcional de la indeterminación en la obra literaria ha sido objeto de estudio de la fenomenología hermenéutica-Ingarden (1973) el ser (1978)- y la semiótica de Eco (1965). Para los dos primerosel significado dela obra no puede considerarseen esencia sino en acto. El estudio de la obra es indisociable de su efecto sobre el lector. El texto implica un potencial de significados que se actualizan en el acto de leer. D e tales presupuestos se deduce la consideración de la lectura como un acto comunicativo en el que el intercambio de las partes (texto/ lector) da lugar a la transformación de las mismas y al nacimiento del objeto estético. En cada una de las etapas del acto de leer, lo que está ausente, lo no dicho o lo negado ocupa un lugar central en el esquema comunicativo. Estos espacios de indeterminación no bloquean, sino que por el contrario estimulan la actividad representativa del lector a todos los niveles: estructural, cognitivo e ideológico. D e modo semejante Eco comenta el valor de la ambigüedad y la inde terminación dentro de la estética contemporánea: “... l'opera d'arte è un messaggio fondamentalmente ambiguo, una pluralità di significati che convivono in un solo significante" $(1965: 6)$. 
ortisiano Lorenzo non esita a sollecitare la collaborazione del lettore nella ricostruzione del testo, questo sarà un modo non solo per creare degli spazi autonomi d'interpretazione, ma anche per ridurre il grado di chiusura che la forma epistolare necessariamente comporta" (1989:35). Pero esta aparente voluntad democrática se velimitada al ser el propio Lorenzo quien emprende esta labor de reconstrucción. Sus comentarios en ocasiones sirven para vislumbrar situaciones, que de otra forma permanecerían en la oscuridad para el lector. En otras ocasiones, sin embargo, su intrusismo en la narración (como el deW ilhelm en Werther) va más allá de la mera exposición de los hechos. En su notas "Al lettore" y en los fragmentos en tercera persona interpolados entre las últimas cartas, Lorenzo guía la actitud del lector hacia su propia interpretación de los acontecimientos. D etrás de su fría objetividad se esconde la manipulación que implica el mero hecho de clasificar unas cartas.

El texto, pues, invita a la participación del lector y la limita a un mismo tiempo. El espacio narrativo ha sido previamente invadido por el polivalente amigo-interlocutor-lector-editor, Lorenzo. A través de este último vislumbramos a un J acopo atrapado en la red de sus propias contradicciones. El protagonista de U Itime lettere es un ser en el umbral de un cambio que refleja los cambios políticos de Italia en vísperas del Resorgimento. Burgués aristocratizante, gira como una peonza en torno al núcleo magnético de una clase a la que pretendía destruir originalmente y que acaba por absorberlo. La visión pesimista de la naturaleza humana que Jacopo proclama no es sino la manifestación de su personalidad depresiva ${ }^{23}$. Su incapacidad para materializar el más insignificante acto de rebelión política le lleva a escudarse en un nihilismo solipsista que tendrá su ultimación lógica en el suicidio.

${ }^{23}$ La vida del propio Foscolo (poeta, soldado, activista político y profesor universitario) contrasta aparentemente con la inactividad de Jacopo en U Itime lettere. Recordemos, sin embargo, que lo descrito en la novela estan sólo un corto período en la vida del protagonista y que las primeras páginas ya nos presentan a un Jacopo desilusionado y en espera de la muerte. EI texto insinúa una vida anterior que podría ser similar a la del autor de la novela. 


\section{CIRCULOS VICIOSOS: DE LA ORALIDAD A LA ESCRITURA, DE LA ESCRITURA AL ABISMO}

Wo fass ich dich, unendliche N atur?

Goethe

Aber das $\mathrm{N}$ amenlose, Anonyme, wie rufst du's, D ichter, dennoch an? -Ich rühme.

Claudio Guillén define la redacción de una carta como "ese tránsito humilde, primitivo, de la oralidad a la escritura" (1985:168). En U Itime lettere el acto de escribir se convierte para Jacopo en la única posibilidad de afirmación ante la desesperanza amorosa y política ${ }^{24}$. La paradoja de la obra de Foscolo es que este acto aparece encubierto bajo el espejismo de la oralidad. El epígrafe que acompaña al título en las tres ediciones más importantes (Bolonia, 1798; M ilán, 1802; y Zurich, 1816) es una traducción latina deunos versos deT homas G ray: "... naturae clamat ab ipso vox tumulo" ("Ev'n from the tomb the voice of $N$ ature cries"). La voz de la naturaleza, pronto averiguamos, es la voz dominanteen la novela, es decir, la voz de Jacopo ${ }^{25}$. Si este recurso le permite trascendentalizar su discurso, conferirle dimensiones megalomaníacas, las palabras del epígrafe adquieren renovado sentido cuando el lector ha terminado la novela. Entonces comprendemos lo que en el fondo es un grito desesperado en favor de la

${ }^{24}$ Como sugiere M atteo, "Politics and love are strategically paired arenas for Jacopo: the first is social, the second is personal. Failing in both, Jacopo fails in the two basic modes of human existence: the social and the individual. He does not find definition in society or in himself" (1985:61). Al margen de lo cuestionable que es considerar el amor como algo meramentepersonal y lo político como social (el mencionado discurso dela 0 tredad y el narcisismo inherente a la actividad pública aś lo desmienten), la cita de $M$ atteo es pertinente en relación con la negatividad asociada a la figura de Jacopo. A su doble fracaso en el amor y la política se vendrá a sumar su fracaso como escritor, lo cual, como veremos, haceentrar en crisis al proceso literario propiamente dicho.

${ }^{25}$ Laidentificación y el sentimiento de ostracismo que el protagonista experimenta en relación con el mundo natural se manifiesta en numerosos pasajes (véanse por ejemplo las cartas del 20 de noviembre de 1797; 19 de enero, 3-11-17 de abril, 13-15-25 de mayo, 2 de junio, 28 de julio y 7 de septiembre de 1798; 19-20 defebrero, 5-14 demarzo de 1799). En todosellosJacopo proyecta su estado de ánimo en la naturaleza que se revela como madre (acogedora, benéfica, generadora de paz y quietud) o como "matrigna" (destructora y terrible). Esta ambivalencia del mundo natural que genera, a su vez, atracción y repulsión es característica de la estética del romanticismo. Las tesis de Argullol en relación con las artes plásticas pueden muy bien aplicarse al tratamiento del paisaje en Foscolo: "el paisaje en la pintura romántica deviene un escenario en el que se confrontan natural eza y hombre, y en el que éste advierta la dramática nostal gia que le invade al constatar su ostracismo con respecto a aquélla" (1983:10). 
creación artística como fuente de inmortalidad. El poeta, voz de la naturaleza, es capaz de trascen der la muerte mediante el acto de la escritura. Pero esta capacidad queda en entredicho en el propio discurso de Jacopo. Las mismas contradicciones que frustran su discurso sentimental e ideológico se reproducen, con mayor fuerza si cabe, en el plano de la creación. En la ya mencionada undécima carta (20 de noviembre), al intentar describir la belleza del paisajey dela propia Teresa, Jacopo se enfrenta con las constricciones del lenguaje para expresar lo que es de por sí inefable:

Se potessi dipingerti la sua pronunzia, i suoi gesti, la melodia della sua voce, la sua celeste fisonomia, o trascrivere almeno tutte le sue parole senza cangiarne o trasl ocarnesillaba, certo chetu mi sapresti grado; diversamente, incresco perfino a mestesso. Chegiova copiare imperfettamenteinimitabile quadro, la cui fama soltando fa più impressione che la tua misera copia? (147-148) ${ }^{26}$.

La escritura como problema pasa así a ocupar el primer plano de la narración junto a los otros motivos apuntados (la imposibilidad de su amor apasionado, la desintegración de Italia y el anhelo de muerte). En la propia textura de las cartas se reproduce la personalidad esquizoide que veíamos en el discurso político del protagonista. Junto al tono general de las cartas quepretende revelarse como espontáneo, casi oral (aunque este efecto de oralidad no es más que un recurso literario), se entrecruzan pasajes de una extraña artificiosidad. Estos últimos son especialmente frecuentes en las descripciones del mundo natural:

S'apriva appena il più bel giorno d'autunno. Parea che la notte seguita dalle tenebre e dalle stelle fuggisse dal sole, che uscia nel suo immenso splendore dalle nubi d'oriente, quasi dominatore dell'universo; el'universo sorridea. Le nuvole dorate e dipinte a mille colori salivano su la volta del cielo che tutto sereno mostrava quasi di schiudersi per diffondere su i mortali le cure della divinità. Io salutava a ogni passo la famiglia de' fiori e dell'erbe che a poco a poco alzavano il capo chinato dalla brina. Gli alberi susurrando soavemente, faceano tremolar contro la luce le gocce transparenti della rugiada; mentre i venti dell'aurora rasciugavano il soverchio umore alle piante. Avresti udito una solenne armonia spandersi confusamente fra le selve, gli augelli, gli armenti, fiumi, el efatiche degli uomini; eintanto spirava l'aria profumata dalleesal azioni chelaterra esultante di piaceremandava dallevalli edai monti al Sole, minostro maggiore della $N$ atura (146-147).

${ }^{26}$ Esta misma situación había sido descrita por G oethe. En Werther el protagonista selamenta de ser incapaz de expresar mediante el lenguaje la belleza de Lotte: "C ependant, Werther, qui autrefois dessinait abondamment et bien, ne peut faire le portrait de C harlotte... ' J'ai perdu... la force sacrée, vivifiante, avec quoi je créais autour de moi des mondes'" (Barthes 1975:113). 
A bundan en este fragmento las figuras conceptistas heredadas del barroco y del neoclasicismo ${ }^{27}$. Aunque en esta carta temprana Jacopo ensaye una posible salida a su dilema personal - la afirmación de su Yo mediante el acto de la escritura en toda su artificiosidad-, el intento se revela fútil. N o es la voz de Jacopo la que habla, sino la de la tradición. Una tradición que dicta las normas que precisamente desafiaba el movimiento romántico ${ }^{28}$. En el resto de la novela la voz narrativa se empeñará en recalcar la inefabilidad de todo lo bello y la impotencia del artista para plasmar tal belleza sobre el papel o el lienzo ${ }^{29}$. Esta permanente ambivalencia entre el deseo compulsivo de escribir, de trascender, por

${ }^{27} \mathrm{M}$ atteo comenta el acusado contraste entre la rigidez de este pasaje, que atribuye a la estética barroca, y la aparente libertad del resto de la novela. Para M atteo, el fragmento citado es representativo de la ambivalencia característica del discurso de Jacopo: por un lado, contribuye a establecer la autoridad de Jacopo como narrador, por el otro, busca ganarse la simpatía del lector mostrando la capacidad del personaje para apreciar la belleza del mundo natural. El estilo de la narración se revela a un mismo tiempo como alienante y seductor, aunque en el ejemplo en cuestión domina la primera de tales características. M atteo analiza en estos términos el mecanismo retórico y el convencionalismo de la mencionada descripción paisajística:

The passage is constructed by a remarkable series of conceits, the predominance of which makes it possible to label the passage as "Baroque". From the first metaphor of the night and the stars fleeing from the advancing sun; through the personification of the similing universe, and "la famiglia de' fiori edell'erbe che a poco a poco alzavano il capo chinato dala brina"..., and the whispering trees; to the final personification and antonomasia of the sun as Nature's greatest "minister," the passage is a continuous chain of rhetorical tropes (1985:86).

${ }^{28} \mathrm{~L}$ a estética de Werther es más coherente en este sentido. La prosa de $G$ oethe se libera de las constricciones del clasicismo pero, además, hace explícita esa liberación mediante los comentarios airados del protagonista:

I $x$ is possible to say a good deal in favor of rules, about as much as can be said in praise of bourgeois society. The person who takes his direction from rules alone will never produce anything in bad taste, in the same way as the person who allows himself to be sahped by rules of social convention can never become an intolerable neighbor or a conspicuous villain; on the other hand, any rule is likely to destroy both the true feeling of $\mathrm{N}$ ature and its true expression, whatever people may say to the contrary (1971:14).

${ }^{29}$ En su carta del 14 de mayo de 1798, Jacopo expresa claramente la incapacidad del arte en todas sus modalidades para reflejar el esplendor de la naturaleza:

$M$ a... se anche fossi pittore? ho veduto ne' pittori ene' poeti la bella e tal volta anche la schietta natura, ma la natura somma, immensa, inimitabile non l'ho veduta dipinta mai. 0 mero, D ante, e Shakespeare, i tre maestri di tutti gl'ingegni sovrumani, hanno investito la mia imaginazione ed infiammato il mio cuore: ho bagnato di caldissime lagrime i loro versi; e ho adorato le loro ombre divine come se le vedessi assise su le volte eccelse che sovrastano l'universo a dominare l'eternità. Pure gli originali che mi vedo davanti mi riempiono tutte le potenze dell'anima, e non oserei, Lorenzo... non oserei, se anche si trasfondesse in me M ichelangelo, tirarne le prime linee (195-196). 
tanto, la simpleoralidad, y la tendencia a privilegiar lo natural como "esencia", la palabra hablada como "verdadera" (frente a la supuesta falsificación de la literatura), revela el impulso paradójico que guía el pensamiento de Jacopo. En términos deconstructivistas podíamos definirlo como la sustitución de un centro (la tradición literaria) por una nueva jerarquía (la creación de un lenguaje de la espontaneidad) que sustituye a la anterior y se manifiesta, en última instancia, tan inoperante como ésta ${ }^{30}$.

Por otra parte, los clisés y las imágenes características de la tradición producen un contraste estridente con la naturalidad y, a menudo, el descuido de la voz narrativa en la mayor parte de las cartas. Estos dos estilos reclaman, a su vez, dos tipos diferentes de audiencia: el lector informado y competente, capaz de captar el significado de las imágenes a la luz de la tradición literaria en la que se inscriben y un tipo de lector ávido de rupturas, quebusca en el desenfado y la libertad estilística del narrador una salida a las trabas formales del neoclasicismo.

D e nuevo, la tensión narrativa surge de una oposición entre tendencias de carácter contradictorio. La búsqueda de un nuevo lenguaje y de una nueva audiencia burguesas se mantiene bajo la estrecha vigilancia de la tradición aristocratizante. El narrador desea huir del centro simbólico de dicha tradición, pero es incapaz de sobrepasar su marco. Jacopo queda atrapado en los márgenes. Esta situación es dramatizada por el propio texto. En los momentos finales de la novela Jacopo no tiene fuerzas para proseguir su labor epistolar. Su única actividad relacionada con el acto de escribir consiste en anotar pensamientos al margen de las obras de Plutarco, M arco Aurelio y T ácito. Todo su afán queda reducido a una simple nota a pie de página de los clásicos. Sus últimas palabras, de

Teniendo en cuenta la admiración que Jacopo dice profesar por todos estos clásicos que cita no ya sólo en este pasaje sino a lo largo de toda la novela, el fragmento en cuestión debe interpretarse como un acto de rendición, una aceptación de la futilidad del acto de escribir y, por lo tanto, como un indicio más del discurso suicida del protagonista.

${ }^{30}$ Siguiendo al gunos de los conceptos expuestos por D errida (1967a), podríamos interpre tar la búsqueda de acopo como una metáfora de esa otra búsqueda que ha dominado el pensamiento occidental desde sus orígenes: la mencionada búsqueda de un centro que garantice el ser como presencia. Términos tales como ser, esencia, sustancia, verdad, forma, principio, fin, propósito, conciencia, hombre, Dios, etc., actúan como principios centralizadores. Derrida descarta la posibilidad depensar fuera deestos términos. Lo único que podemos hacer es evitar que uno de los polos del sistema se convierta en un nuevo centro que garantice esta presencia ilusoria. El error de Jacopo, su nuevo suicidio discursivo, se produceal no ser capaz dearticular las ambivalencias de su pensamiento, privilegiando siempre uno de los dos términos de la oposición, esto es, pensando siempre en términos absolutos. Tras sucesivos intentos por hacer del amor y la lucha política ese vehículo de afirmación, Jacopo experimenta la misma frustración en el acto de escribir. Pero su desconfianza en el valor de la escritura (algo característico del pensamiento "logocéntrico"), le lleva a renegar de su única posibilidad de salvación. 
hecho, son citas de Alfieri y $D$ ante (dos nuevosjalones - renacimiento y neoclasicismo- dentro de la genealogía clásica italiana). En uno de sus últimos encuentros con el Signor $T^{* * *}$ Jacopo se vale de un pasaje de Alfieri para comunicar su intención de suicidarse:

\author{
Non diedi a voi per anco \\ Del mio coraggio prova: ei pur fia pari \\ Al dolor mio (270).
}

D e modo similar, cuando Jacopo poco antes de morir visita a su madre en Venecia, descubre un retrato suyo pintado por Teresa. El cuadro muestra un verso de D ante "Libertà va cercando ch'è sì cara" (464). A través del comentario de Lorenzo sabemos que es el padre de Teresa quien le había sugerido la inscripción, revelándose una vez más como portavoz de la tradición. El verso es completado por Lorenzo, que asume así el mismo papel queil Signor T***: "Come sa chi per lei vita rifiuta" (464) 31. La escena no sólo sirve para justificar la muerte de Jacopo como una especie de inmolación patriótica. Adivinamos desde los comienzos de la novela un progreso que bien podríamos calificar de regresión cíclica, de círculo vicioso: de los intentos de reforma, Jacopo pasa a aceptar el Establishment, pero las contradicciones entre estos dos tipos de discurso político le llevan a abandonar el acto de escribiri ${ }^{32}$. Su discurso último consisteen una oralidad oximorónica, ya que no se revela como espontánea (rasgo asociado al habla), sino artificiosa (característica de la escritura): J acopo habla la literatura escrita. El impulso que le movía a intentar dar expresión a un lenguaje literario que fuera al mismo tiempo oral y escrito, sin desprenderse del lastre de la tradición acaba por emplazarlo en un nuevo callejón sin salida, donde Jacopo es nuevamente aniquilado.

La forma en que Jacopo lleva a cabo su suicidio contiene un alto potencial simbólico. En los instantes finales podemos ver reunidos muchos de los temas que hemos venido anotando. Al igual que en Werther, el escenario de la muerte del héroe se corresponde con lo que Derrida (1967b) Ilama "la scène de l'écriture" 33 . H asta el último momento Jacopo intenta escribir varias cartas que

\footnotetext{
${ }^{31}$ L os versos de $D$ anteaparecen como epígrafeen la primera página de la edición londinense de 1817, lo que, además de dar al texto una nueva nota ominosa, confiere a la psicología de personaje principal un carácter recurrente.

32 El rechazo de la escritura se manifiesta de forma violenta mediante la quema de cartas y escritos, especialmente al final de la obra, cuando la frustración de Jacopo ante los límites del lenguaje se hace más obsesiva $(141,267,276)$.

${ }^{33}$ En la página final de la novela de $\mathrm{G}$ oethe, W ilhelm, en su meticulosa descripción, no escamotea los detalles macabros: "From the blood on the back of the armchair they concluded
} 
quedan reducidas a si mples borradores, fragmentos llenos de tachaduras y frases inarticuladas. Junto a su escritorio se clava una daga en el pecho y, aunque no consigue atravesar el corazón, muere desangrado en los brazos del Signor T***. En el momento en que el puñal se hunde en su pecho pronuncia "un lungo gemito". La supremacía del sentimiento simbolizada en el corazón ("tutto dipende dal cuore") es víctima de la agresión final de Jacopo, aunque no es directamente destruida. En un extraño gesto final de abrazo y de rechazo del padre de Teresa, Jacopo manifiesta de nuevo la ambigua mezcla de atracción y repulsión que siente por estepersonaje $\mathrm{e}^{34}$. El último mensaje no es, lógicamente una carta, sino un gemido, una vuelta no ya a la simple oralidad, sino a aquella que precede a la articulación lingüística del pensamiento, una regresión al primer sonido emitido al nacer ${ }^{35}$. Con este gemido, Jacopo, la voz de la naturaleza, vuelve a ella, para disolverse en el abismo.

\section{REFERENCIAS}

Altman, Janet Gurkin. 1982. Epistolarity: Approaches to a Form. Columbus: O hio U P. Argullol, Rafael. 1982. El héroey el único: El espíritu trági co del Romanticismo. M adrid: Taurus.

. La atracción del abismo: Un itinerario por el paisaje romántico. Barcelona: Bruguera.

Bakhtin, M ikhail. 1984. Problems of D ostoevskys Poetics. Trans. Caryl Emerson. $M$ inneapolis: $U$ of M innesota P.

Barthes, Roland. 1977. Fragments d'un discours amoureux. Paris: Editions du Seuil. Berengo, M . (ed.). 1981. Lezioni sul Foscolo. Firenze: La N uova Italia Editrice. Binni, Walter. 1982. U go Foscolo: Storia e poesia. Torino: Giulio Einaudi. Cambon, Glauco. 1980. U go Foscol o: Poet of Exile. Princeton: Princeton U P.

that he dad committed the act while sitting at his writing desk. He had then slid down and rolled around the chair in convulsions" (1971:166).

34 "Il signore $T^{* * *}$ gli sollevava lievemente dalla ferita la camicia, che tutta inzuppata di sangue gli si era attaccata sul petto; Jacopo si risenti; ed alzò il viso verso di lui e guardandolo con gli occhi nuotanti nella morte stese un braccio per impedirlo, e tentava con l'altro di stringergli la mano... ma ricascando con la testa sui guanciali, levò gli occhi al cielo e spirò" (289).

${ }^{35}$ El gemido final de Jacopo manifiesta la regresión del lenguajea ese estado primordial que Lacan Ilama Lalangue y que Jacques Alain-M iller interpreta como "a pregrammatical and prewritten level of language" (1990). Lalangue, como señala Lacan, trabaja al nivel del sonido. Es esa especie de masa verbal informe sobre la que está construida la gramática: "Lalangue, as one word (without an article or with the article soldered onto the substantive, instead of la langue): general equivocation, universal babble, or 'Babelonian'” (Lacan 1990:6). 
Carpanetto, Dino y Gino Ricuperati. 1987. Italy in the Age of Reason: 1685-1789. London and N ew York: Longman.

Dapelo, C. 1953. "Werther e 0 rtis". L ettere italiane 5: 176-186.

Derrida, Jacques. 1967a. D ela G rammatologie. Paris: M inuit.

-

Eco, U mberto. 1967. O pera aperta: Forma e indeterminazione nelle poetiche contemporanee. Milano: Bompiani.

Foscolo, U go. 1970. Edizione N azionale delle 0 pere di U go Foscolo. Vol. IV: U Itime lettere di Jacopo 0 rtis. G iovanni G ambarin (ed.). Firenze: Felice Le M onnier.

Frattini, Alberto. 1965. II neoclassicismo eU go Foscol o. Rocca San C asciano: Cappelli.

Goethe, Johann Wolfgang Von. 1971. The Sorrows of Young Werther and N ovella. Trad. Elizabeth M ayer and Louise Bogan. N ew York: Random H ouse.

Goethe, Johann Wolfgang Von. 1989. Las desventuras del joven Werther. Trans. M anuel José G onzález. M adrid: Cátedra.

Guillén, C laudio. 1985. Entre lo uno y lo diverso: Introducción a la literatura comparada. Barcelona: Editorial Crítica.

---------. 1989. Teorías de la historia literaria: Ensayos de teoría. M adrid: Espasa-Calpe.

Graff, A. 1895. "Su Le ultime lettere del Foscolo e il Werther del Goethe". Nuova Antologia 57.

H earder, H arry. 1987. I taly in the Age of the Risorgimento 1790-1870. London and N ew York: Longman.

Ingarden, Roman. 1973. The LiteraryWork of Art: An Investigation on to the Borderlines of O ntology, Logic, and the Theory of Literature. Trans. George. G. Grabowicz. Evanston, III: N orthwestern UP.

Iser, Wolfgang. 1978. The Act of Reading: A Theory of Aesthetic Response. Baltimore: Johns H opkins U P.

Lacan, Jaques. 1990. Television / A Challenge to Psychoanalytic Establishment. Ed. J oan Copejec. Trans. D enil H ollier, Rosalind Krauss, Annette M ichelson, and Jeffrey M ehlman. N ew York: N orton.

M anacorda, G iuseppe. 1973. M aterialismo emasochi smo: II "Werther", Foscolo e L eopardi. Firenze: La N uova Italia.

M arpillero, G. 1900. "Werther, O rtis e il Leopardi". Giornale storico della letteratura italiana 36: 350-78.

M assano, Riccardo. 1965. "G oethe eFoscolo, Werther e O rtis". En Problemi di lingua eletteratura italiana del Settecento. Associazioneinternazionaleper gli studi di lingua e letteratura italiana. W iesbaden: Franz Steiner Verlag, 231-238.

$M$ atteo, Sante. 1985. Textual Exile: T he Reader in Sterne and Foscolo. N ew York: Peter Lang.

M iller, Jacques-Allan. 1990. "A Reading of Some D etails of Lacan's Television / A Challenge to Psychoanalytic Establishment in Dialogue with the Audience". The Lacan Conference 1990. Barnard College. N ew York, 14-15 April.

Nicoletti, Giuseppe. 1978. II "metodo dell'O rtis" e altri studi foscoliani. Firenze: La N uova Italia Editrice.

Pugliese, Guido (ed.). 1989. Perspectives on N ineteenth-Century Italian N ovels. O ttawa: D overhouse Ed. 
Radcliff-U mstead, D ouglas (ed.). 1970a. U go Foscolo's U Itime Lettere di Jacopo O rtis. A Translation. Chapel H ill: The U of N orth Carolina P.

-.-.-.-. 1970b. U go Foscolo. N ew York: Twayne.

Rimmon-K enan, Shlomith. 1983. Narrative Fiction: Contemporary Poetics. London and N ew York.

Selden, Raman. 1986. A Reader's Guide to Contemporary Literary Theory. Brighton: The $\mathrm{H}$ arvest Press.

Todorov, Tzvetan. 1984. M ikhail Bakhtin: The Dialogical Principle. Trans. W lad Godzich. M inneapolis: $U$ of M innesota P.

Varese, Claudio. 1982. Foscolo: Sternismo, tempo e persona. Ravenna: Longo Editore.

Zumbini, B. 1930. "Werther e Jacopo O rtis". En Studi di letteratura comparata. Bologna: Zanichelli. 